\title{
Insect history
}

\author{
Frederick R. Schram \\ Institute for Biodiversity and Ecosystem Dynamics, University of Amsterdam, Mauritskade 57, I092 AD \\ Amsterdam, The Netherlands
}

Review of: History of Insects, edited by A. P. Rasnitsyn and D. L. J. Quicke. Kluwer Academic Publ., Dordrecht, Netherlands, 2002, 517 pp., ISBN $140200026 \mathrm{X}$

In the winter of 1977, I visited the Paleontological Institute of the Academy of Sciences in Moscow. I wanted to study the type specimens of fossil crustaceans, which were housed in the Laboratory of Paleoentomology. I thought that strange at the time, but then there were not many fossil crustaceans known from Russia and guessed that someone had decided that the collection for fossil hexapods was the best place to store the shrimp. It was on that occasion that I first encountered the fossil insect research group under the direction of Prof. Boris Borissevich Rohdendorf. It surprised me to discover that there were about 12 paleoentomologists working in that laboratory, more paleoentomologists than there were in the whole of the rest of the world. Looking back on those times, my ignorance should not have been too surprising. There was much that we in the West did not know about our colleagues in the old Soviet Union, and vice-versa. I brought along a stack of my reprints as 'a gift, and Prof. Rohdendorf eagerly grabbed them and retreated to his desk in the corner of the room. I felt honored that he was so interested in my work until I saw that he was ignoring my texts and thumbing through the reference lists. "Excuse me," he looked up and said, "It is not that I have no interest in your work, but for us it is also important to see what papers you used in your research. We know so little about western literature." I felt the same away about Russian fossil insect studies.

During the rest of that visit, and for years afterward as members of that laboratory and I exchanged reprints, I learned more about the Russian school for fossil insect reseärch. Not only were they studying insect body fossils in Moscow, they were also employing things like insect trace fossils to document the microstratigraphy of remote areas of Soviet Siberia. Two of the most important figures in the laboratory were Alexander Pavlovich Rasnitsyn, who is the senior editor of this volume, and Vladimir Vasilievich Zherikhin, one of the principal contributors to this book who unfortunately passed away before the volume was published.

As reprints arrived from the Moscow group over the years, I thought how critical it would be to get a better exposure of their work on fossil insects beyond the limited readership of Russian scientific literature. This exposure occurred in part with the publication of Carpenter's (1992) volumes on fossil insects, but that work, years in production, was little more than a taxonomic catalog. With the Rasnitsyn and Quicke treatise we now have a book that more adequately reflects the richness of the material available for study of insect history.

The text of this volume is divided into three large sections: an introduction to paleoentomology, a review of the insect fossils group by group, and a presentation of general aspects of insect evolution.

The first section entails a nice introduction to the study of insect fossils suitable for a course in the subject. However, it begins with statements that many readers will find startling: "...cladistics has 
not been universally accepted as the one and only method to be applied to classifying organisms ... many methods are good ... genealogy is not the ultimate goal of taxonomy ... " (pp. 1-3). In fact, the use of cladistics to test phylogenetic hypotheses is not universally accepted in this treatise either, and allusion is made to the Ghost Range Method of Rasnitsyn (2000). These statements very much reflect the outlook of Russian science and are ones that may disturb ardent cladists in the West. Even so, the incompleteness of the fossil record, no matter which approach one might prefer towards analyzing insect diversity, is strikingly illustrated in the maps in Figs. 3-5. These maps record not so much where fossil insects are found as where palaeoentomologists have lived and worked - mostly in the northern hemisphere.

This section also contains a little history of fossil insect studies, which I found nicely done with lots of pictures of people. The chronicle extends from the time of Linnaeus but more-or-less stops with Rohdendorf (1904-1977) and the Moscow School. The following chapter by Zherikhin on the "Pattern of Insect Burial and Conservation" is the sort of thing Carpenter (1992) should have included, and it covers the subject in a manner that beginning students might find interesting and informative.

The second, and by far the largest, section of the book (some 260 pages) covers the systematics of Insecta. Rasnitsyn (p. 65) settles on one particular view of the organization of the insect head. Segment 1 is the fore part of the head, whose "appendages fused into the labrum" and whose ganglia evolved into the protocerebrum. Segment 2 bears the antennae and compound eyes enervated by the deuterocerebrum. Segment 3 , the intercalary segment of many authors, contains the tritocerebrum and has suppressed the appendages. Segments 4-6 bear the mouthparts. This interpretation is very much along the lines of Eastham (1930). However, head evolution in the insects is a complex subject characterized by a variety of authoritarian opinions. It would have been nice to have some of these alternative viewpoints presented for comparison, but one can consult Rempel (1975) for details.

Rasnitsyn takes the opportunity to summarize at length the ideas of Shcherbakov (1999) on the ori- gins of Insecta, wherein hexapods are viewed as neotenous syncarid crustaceans. This is not a new idea (Boudreaux, 1979), but it is an explanation that $\mathrm{I}$ believe is too easy. Syncarids, for the most part ground water and interstitial malacostracans, include only one group that is large bodied and, with the lack of wings and a carapace, thus somewhat evocative of apterygote insects. However, this viewpoint rather ignores many aspects of the distinctly different Baupläne of malacostracan crustaceans and hexapods, including the location of gonopores and the expression patterns of $H o x$-genes. Alternative hypotheses of insect relationships to crustaceans are possible (see Schram \& Jenner, 1999). For example, the location of gonopores and expression patterns of $H o x$-genes might find easier accord if one compared insects to branchiopod crustaceans. In addition, Shcherbakov asserts that both remipedian crustaceans and myriapods are highly modified and rather casually rejects the "common opinion" that these groups are primitive. I would be quite willing to entertain Shcherbakov's alternative hypothesis, but I would like some evidence to support his contention - something other than vague comparisons to "legless vertebrate analogues" (p. 67). Nevertheless, I appreciated having this summary of Shcherbakov, which heretofore had lain largely hidden in the Russian literature.

The rest of section two contains a taxonomic survey. I liked this part. It is well illustrated with photographs of specimens that are for the most part clear and of good quality, and it is nicely augmented in places with attractive diagrams. Furthermore, each taxon has a text containing introductory comments, a definition of the group, the synapomorphies that diagnose that taxon, the geologic range, comments on the systematics and phylogeny, and various remarks on the historical genesis of the group. These summaries are really useful and contain ample references to the genera, and occasionally families as well, that are currently placed within the group. Furthermore, the text is quite readable, and the extra effort of careful editing here has paid handsome dividends.

However, readers may be hindered in their use of this section by what may appear to be a strange higher taxónomy. There is of course no priority 
Table 1. A partial comparison of the how the higher taxonomy of some of the "primitive" hexapods is handled in History of Insects as opposed to Carpenter's Treatise on Invertebrate Paleontology.

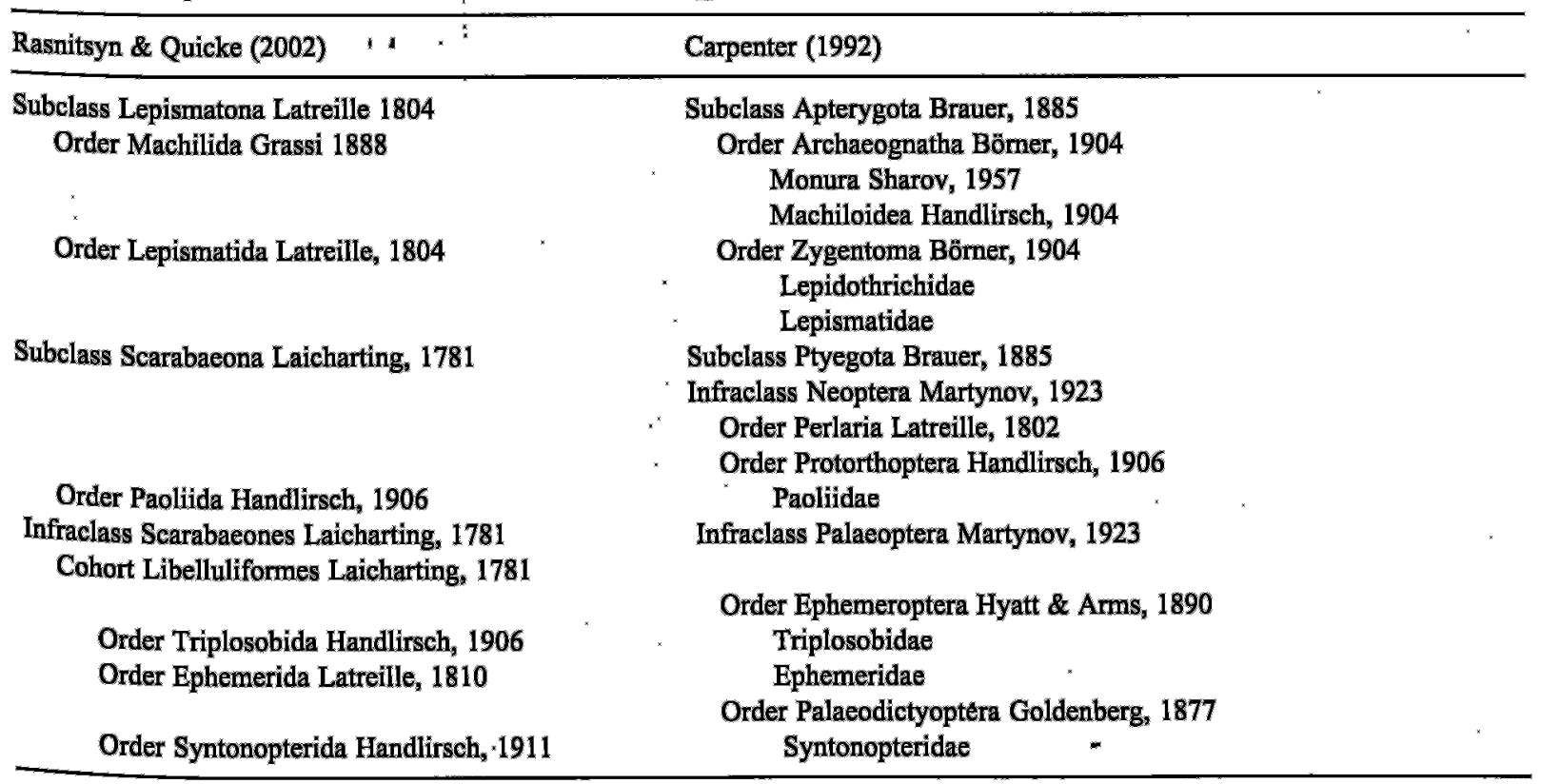

when it comes to names above the family level. Furthermore, reputable authorities often differ in their judgements as to where to place certain problematic taxa. Nevertheless, choice of historically older names in lieu of more easily recognized ones may well cause the user of this book some difficulties. The table herein illustrates the point by comparing part of the taxonomy employed in Rasnitsyn and Quicke with the standard catalog of Carpenter (1992) familiar to western paleontologists and those with interests in insect fossils. One can allow for differences of opinion about whether the Paoliidae are either a very primitive early offshoot of the insect line, or a specialized family of neopterans. However, it will take an effort to gain familiarity with terms like Lepismatona and Scarabaeona in place of the more familiar Apterygota and Pterygota. These strange names hinder understanding. Indeed, one may even be tempted to ask "Why did they use them?"

A very useful feature of this section, however, is the way in which diagrams of geologic ranges are combined with phylograms of the groups in question with the branch points clearly keyed to apomorphic features provided in the legends. $\mathrm{Al}-$ though the text does not contain separate sections for families and superfamilies, these are in fact featured in these range diagrams. As effective as this section is towards covering the great array of ancient insect biodiversity, the informed reader might still want to have a copy of Carpenter (1992) near at hand.

The last section of the book takes up "General Features of Insect History" in several large chapters. These include an overview of insect diversity through time, paleoecology of terrestrial insects, another on paleoecology of aquatic insects, and finally an overview of insect paleogeography. It is here where I think the book has some problems. While I found Eskov's chapter on paleobiogeography full of facts (the sort that tell us what was present, when and where), I would have welcomed a more explicit use of cladistics in this connection. We could have seen some testable hypotheses of insect deep history, more akin to what was undertaken by Amorim (2002), wherein actual phylogenetic relationships were linked to paleogeography. Alas, this was not done.

The volume closes with a listing of selected sites that have proven important for insect paleontology. The little paragraphs describing each locality contain references to important papers on that site in 
the literature and refer to the figures in the book upon which the site is mapped. The references comprise 46 pages, and as one would expect it is heavy on citations in the Russian literature. The list appears to be fairly complete, though I did notice that a few items on the insects of the Carboniferous Mazon Creek biota were missing.

This treatise will constitute an effective reference to consult when details about the history of insects are needed. The text is remarkably free of Russianized transliterations. Thus, the reader will have little trouble with the strange jargon that often mars too literal translations of original Russian texts. The production is high quality, with good stock and crisp halftones. The price, $\$ 224$, or $€ 240$, or $£ 149$ will deter a lot of people from purchasing a personal copy. That would be a pity. Hopefully libraries will not be so inhibited.

\section{References}

Amorim DS. 2002. How advanced was Diptera evolution in the Pangaea? Annal. Soc. Entomol., France. 38: 177-200.

Boudreaux HB. 1979. Arthropod Phylogeny with Special reference to Insects. John Wiley, New York.

Carpenter FM. 1992. Treatise on Invertebrate paleontology, Part $R$, Arthropoda 4, vols. 3 \& 4: Superclass Hexapoda. Geol. Soc. Amer. \& Univ. Kansas Press, Lawrence.

Eastham LES. 1930. The embryology of Pieris rupaea: orgenogeny. Phil. Trans. Roy. Soc., Lond. B. 219: 1-50.

Rasnitsyn AP. 2000. Testing cladograms by fossil record: the ghost range test. Contrib. Zool. 69: 251-258.

Rempel JG. 1975. The evolution of the insect head: the endless dispute. Quaestiones Entomologiae 11: 7-25.

Schram F.R, Jenner RA. 2002. The origin of Hexapoda: the crustacean perspective. In, Origin of the Hexapoda (T. Deuve, ed.). Annal. Soc. Entomol. France 37: 243-264.

Received: 27 January 2003 